\title{
Ergonomics
}

\section{Effects of background noise and extraversion on reading comprehension performance}

\author{
F. Gheewalla , A. McClelland \& A. Furnham
}

To cite this article: F. Gheewalla , A. McClelland \& A. Furnham (2020): Effects of background noise and extraversion on reading comprehension performance, Ergonomics, DOI:

10.1080/00140139.2020.1854352

To link to this article: https://doi.org/10.1080/00140139.2020.1854352

Accepted author version posted online: 19

Nov 2020.

Submit your article to this journal $₫$

山 Article views: 58

Q View related articles $\widetilde{ }$

View Crossmark data \lceil 
Effects of background noise and extraversion on reading comprehension performance.

Gheewalla, F., ${ }^{1}$ McClelland, A. ${ }^{2}$, \& Furnham,A. ${ }^{3}$

(1) Research Department of Clinical, Educational and Health Psychology, University College London, 26 Bedford Way, London, WC1H0AP

(2) Research Department of Cognitive, Perceptual and Brain Sciences. University College London, 26 Bedford Way, London, WC1H0AP

(3) Norwegian Business School (BI), Nydalveien, Olso, Norway

Corresponding author: adrian@adrianfurnham.com 
Effects of background noise and extraversion on reading comprehension performance.

\section{Practitioners Summary}

This study was concerned with whether white noise and the sound of sirens effects reading comprehension. We found that compared to doing a highly involving and demanding cognitive task in silence, siren noise has a most significant negative effect on performance. Compared to working silence, white noise also reduced the efficiency on text comprehension. There were no introvert-extravert effects.

\section{Abstract}

This study was concerned with the effects of acoustic distraction at work. Using a within-subject study we aimed to investigate the effect of background distraction on cognitive performance. In the presence of silence, white noise, and sirens, fifty-five fluent English speakers completed three equivalent variations of a reading comprehension task. As predicted, there was a significant main effect of background sound, with poorer performance in the presence of distraction (particularly sirens), but no interaction was found between distraction and extraversion. Thus, the findings partially replicated previous research in terms of distraction but were inconsistent with regard to the Eysenckian theory of arousal differences between introverts and extraverts. Implications of the effect of sirens on those they are not designed to alert are considered. Limitations of this study are also considered.

Keywords: extraversion; personality; distraction; cognitive performance; background noise 
The effects of distracting stimuli (e.g., background noise, loud music, strong smells, flashing lights) on cognitive performance has been a topic of considerable interest over the last few decades (Cassidy \& MacDonald, 2007; Dobbs, Furnham, \& McClelland, 2011; Furnham \& Strbac, 2002; Ylias \& Heaven, 2003). Arguably the most commonly experienced distractor is background noise, which is generally perceived to be detrimental to cognitive performance (Halin, 2016). This is important in the design and administration of closed and open-planned offices, as distraction can have a major effect on everyday work performance, particularly for knowledge workers.

The academic work in this area has identified three important factors: the nature of the distraction (i.e., music vs noise); the task being undertaken in the presence of the distraction (i.e., memory vs comprehension); and the personality of the individual (i.e., extraversion vs introverts)(Dobbs et al., 2011; Landay, \& Harms, 2019). This study examines the effects of two types of noise, on the reading comprehension of introverts and extraverts. The majority of the research implies that out of all major personality traits, extraversion, the extent to which an individual has a need for stimulation from their social environment to satisfy their arousal needs (Eysenck, 1967, 1994) has the greatest influence on cognitive performance under distraction.

This study employs a within-participant design to increase test sensitivity, includes an investigation of the effect of the sound of sirens on cognitive performance, and uses the time taken to the complete the task, rather than a test score after a fixed time period, as the dependent variable. Both of these factors are novel for research in this area. 
Working in many inner city areas, as well as at home, is becoming more common due to the Covid-19 crisis. Thus a central question concerns the effect of uncontrollable, unpredictable and emotionally arousing sounds such as sirens of any sort on a cognitively challenging task. This is relevant to all knowledge workers and those that employ them, to ensure that their environment facilitates rather than frustrates their efforts. This is one of the first studies to investigate this issue using a within subject design.

\section{Effect of distraction on cognitive performance}

The literature on distraction can be divided into three categories: music, noise and "other". Those studying music have primarily been cognitive and social psychologists, while those studying noise have been applied psychologists and ergonomists. Some studies have compared the distracting effects of both music and noise (e.g., Furnham \& Strbac, 2001), showing that both have effects on performance. The literature on the effects of music on performance has been recently and comprehensively reviewed by Landay and Harms (2019) who concluded that the effect of music on cognition is mediated through mood and emotion. Gonzalez and Aiello (2019) came to a similar conclusion; "we found that music generally impaired performance on a complex task, whereas complex music improved performance on a simple task. These effects depended on the task performer's personality, suggesting the need to consider music-, person-, and task-based factors when deciding whether to integrate music into work environments" (p. 431).

While some previous studies have used a within-subjects design to consider the effects of noise on cognitive processing (e.g. Enser et al., 2017), to our knowledge this is the first to consider the effect of sirens specifically. Studies have examined a 
number of different variables. For example, Banbury and Berry (1998) administered mental arithmetic and prose recall tasks to undergraduates either in the presence of office noise or silence. As predicted, their results revealed that participants' performance worsened in the noise condition.

There is also a literature on different noises' effects on cognitive performance. Halin (2016) looked at the effect of background speech, aircraft noise and road traffic noise compared to silence on the reading ability of students. He found the background sound/noise had a detrimental effect in less cognitively demanding conditions (an easy to read font) and no measurable effect with a demanding task (difficult to read font). Interestingly, when using music rather than noise as a distractor, Furnham and Allass (1999) found that the distracting effect was more apparent with more cognitively demanding tasks.

Jafari, and Kazempour (2013) recommended the application of brain signal and power spectral density analyses to assess cognitive performance during noise exposure. They also suggested exploring psychoacoustic parameters such as tonality, noise pitch (treble or bass) at extended exposure levels.

Certainly, it is possibly to draw on various psychological areas of research to predict and explain results, particularly the use of sirens. From the work on emotion and appraisal, as well as cognitive associationism it is clear that some sounds have powerful affective associations which can have an immediate effect on cognitive performance. There are indeed classic studies on the processing of affective material (Eysenck, 1994. Lavie 2005). Similarly, it is possible to call on learning theory with its understanding of conditioning to understand how certain sounds, particularly those associated with emergencies, fear and trauma, have led to a number of predictable responses. None of these theories attempting to explain results in this area are 
contradictory though they do place an emphasis on different features, that lead to the prediction that sirens in particular should lower cognitive performance.

\section{Effect of personality on cognitive performance}

Eysenck $(1967,1994)$ predicted that individual differences in cognitive performance under distraction could be attributed to the degree of extraversion exhibited by the individual. With the assumption that background sound is stimulating, and possesses the ability to increase levels of cortical arousal, it is plausible that introverts would be

affected by background sounds to a greater degree than extraverts. As introverts already have higher levels of cortical arousal, the presence of background sound would result in over-stimulation thus leading them to show a decline in cognitive task performance when distracted, as they would exceed their optimum levels of cortical arousal.

Matthews and Amelang (1993) found extraversion was the only one of the Big Five personality factors to show a consistent effect on performance in the cognitive tasks, and there has been a small but growing amount of research investigating the interaction between extraversion and background distraction on cognitive performance (e.g. Avila, Furnham, \& McClelland, 2011; Cassidy \& MacDonald, 2007; Dobbs et al., 2011; Furnham \& Allass, 1999; Furnham, Gunter, \& Peterson, 1994; Ylias \& Heaven 2003). Belojevic et al. (2003) argued that the contradictory and confusing results in noise research may be due to a neglect in the study of individual differences. They noted that in many studies, introverts demonstrated a higher sensitivity to noise when performing cognitive tasks compared to extroverts. In contrast, extraverts would request short bursts of noise when performing a boring 
task. These results suggest that those with high noise sensitivity (introverts) may perform less well that more extraverted individuals in a noisy environment.

Shepherd et al. (2015) investigated the relationship between the Big Five personality dimensions and self-reported noise sensitivity. They found that overall, the Big Five accounted for $33 \%$ of the variance in noise sensitivity, with the Introversion-Extraversion dimension explaining the most variability. Mohammed et al. (2018) looked at the effects of low frequency noise on the cognitive performance of 120 medical students, and found that in the presence of the noise, extraverts outperformed introverts.

These studies have suggested that the type of noise, most particularly its loudness, along with task complexity, are the most important factors determining whether it interacts with personality factors - particularly extraversion - which is implicated in noise sensitivity.

One central question concerns the explanation for these particular findings. One possibility lies in cognitive load theory (Lavie, 2005). The load theory of attention and cognitive control proposes that the extent to which people can focus their attention in the face of irrelevant distractions depends on the level and type of information load involved in their current task. The extent to which unattended information is processed depends on the load of the attended task, such that increasing the level of load in the task decreases processing of task-irrelevant stimuli. Loading executive control results in increased processing of irrelevant stimuli: thus noise in a work environment overloads the information processing system resulting in less efficiency. 


\section{This Study}

The main aim of the present study is to investigate the use of a type of background noise - police sirens - which we believe have not been investigated before. Sirens are a frequent background noise particularly in big cities such as London, which was the location for this study. The experience of hearing sirens in the background is out of an individual's control, and usually cannot be predicted. Smith (1989) suggested that individual differences affects sensitivity to noise stressors, and that this sensitivity changes with the perceived distress associated with the stressor. We assume that hearing a siren (a signal for danger) would be more stressful than hearing white noise (presumed to be neutral with respect to danger) of the same level of loudness - and both would be more distracting than silence. These represent the three conditions in the study. Thus, it is not only the loudness (and uncontrollability) of the noise stimulus but what it symbolises that is of potential importance with respect to distraction.

Taking test scores as a measure of cognitive performance in distraction scenarios assumes that distraction results in a deficit in ability, leading to a lower test score on a particular cognitive task. We argue that distraction may instead lead to a slowing of cognitive processes. For this reason, we have chosen to measure performance using the time taken to complete the task under each distraction condition.

To ensure the differences in time taken reflect cognitive performance, three variations of a low-effort reading comprehension task designed for school children will be used. These tasks were piloted for ceiling effects and indeed showed that little cognitive effort was required to score full marks. This also revealed that all three variations were of equal difficulty. 
Most importantly, and relatively uniquely in this growing literature we employ a within subject design which is always preferable in accounting for other salient factors like intelligence, motivation (Charness, Gneezy, \& Kuhn, 2012).

Therefore, the hypotheses for the present experiment were as follows:

1. There would be a main effect of background noise such that all participants' reading comprehension performance would be best in the silence condition, followed by white noise, and worst in the presence of police sirens.

2. There will be no correlation between reading comprehension performance and extraversion in the silence condition. However, in noise conditions, there will be a significant negative correlation, such that participants scoring higher on the extraversion assessment will take less time to complete the task than those with a lower extraversion score.

\section{Method}

\section{Participants}

Fifty-five fluent English speakers with no known auditory impairment took part in this study. Of these participants, 15 were male and 40 were female with an age range of 18-38 years $(M=21.75$ years, $S D=4.28$ years $)$. The participants were recruited via an online advertisement or through the departmental subject pool. Participants were not paid, but those recruited through the subject pool received course credit. An a priori power analysis was conducted using $\mathrm{G}^{*}$ Power (Faul, Erdfelder, Lang, \& Buchner, 2007) indicated that to detect a standardised effect size of $f=0.25$ (moderate), with a 5\% significance level and $95 \%$ power, the minimum sample size required was 43 individuals. 


\section{Stimuli and Apparatus}

Sounds. Two types of sound were used in this study: white noise and police sirens. Both sound clips were taken from www.freesound.org. The white noise track (http://freesound.org/people/theundecided/sounds/165058/) was a five minute recording. The sirens track was a 62 second recording and was a mixture of the three different wails made by London police sirens, (http://freesound.org/people/vlammenos/sounds/52906/). Both tracks were played on a loop through headphones at $85 \mathrm{~dB}$ for the duration of each task.

Reading Comprehension Task. Three versions of a reading comprehension task were used in this experiment. This was necessary because we had a within-subject design such that each participant read each of three different passages under three different distraction conditions. They were all grade five practice reading tests from Pearson Longman (Pearson Education, 2012) that consisted of a short passage followed by five multiple-choice comprehension questions. These tests were specifically chosen to be easy for a fluent English reader.

The reading comprehension tasks were administered to participants using Qualtrics survey software (Qualtrics, 2005) and were presented on a standard laboratory computer set-up. Each version was presented on a separate page, followed by the forced choice questions. Participants could not continue until submitting an answer to each question.

Extraversion Questionnaire. The pen-and-paper questionnaire given to participants consisted of 12 items to which participants could respond 'yes' or 'no'. It was scored 
on a 13-point scale of $0-12$ (introversion to extraversion) (Eysenck, Eysenck, \& Barrett, 1985). It has an Alpha of .83.

\section{Procedure}

Ethical approval was sought and granted. Participants were first given the information sheet and an opportunity to ask questions, after which they provided informed consent. They were then given the personality questionnaire. On completion of the questionnaire, participants were directed to the computer in front of them and asked to place their headphones on to begin the reading comprehension passages. They were asked to answer the questions as quickly and as accurately as possible. While the participants were completing the three versions of the task, the experimenter measured the amount of time they took in each condition using a stopwatch. Partial counterbalancing was achieved with participants being randomly allocated to task/background noise combinations using a classic Latin Square design (Dénes, \& Keedwell 1974).Within a given combination, the order of the tasks and the order of questions within each task were also randomised.

\section{Results}

Participants took between 660 and 780 seconds to complete the questionnaire and comprehension tasks. Three of the participants were excluded for incorrectly answering one or more questions when completing the reading comprehension task. A further two participants identified as outliers and were excluded as their times were more than two standard deviations away from the mean. Hence, the following analyses were based on the data from the remaining 50 participants where each participant completed each task in each condition. 
The mean extraversion score was $6.70(S D=3.09)$, which is consistent with the norms for their age group (Eysenck et al., 1985). Inspection of Table 1 reveals that, on average, participants completed the comprehension task most rapidly in silence, followed by white noise and then sirens.

\section{Insert Table 1 here}

Effects of background noise. A repeated measures ANOVA was conducted to investigate the effects of background noise on reading comprehension performance. As the assumption of sphericity was violated (Mauchly test: $\chi^{2}(2)=12.07, p=.002$ ) a Greenhouse-Geisser correction was used to adjust the associated probabilities obtained from the analysis. A main effect of background noise was found, $F(2,98)=$ $48.17, p<.001, \eta_{\mathrm{p}}^{2}=49.6 \%$ indicating that there was a significant difference in the amount of time taken by participants to complete the tasks under the three different sound conditions. Two post-hoc, Bonferroni-corrected paired samples $t$-tests were conducted to further investigate the effect of background noise. The difference in completion time was between the silence white noise conditions was significant, $t(49)$ $=5.21, p=<.001, d=0.74$. In addition the difference between the white noise condition and the sirens conditions, was also found to be significant, $t(49)=5.76, p=$ $<.001, d=0.82$. Thus white noise impaired performance relative to silence, and in turn, sirens impaired performance relative to white noise.

Effects of Extraversion. To investigate the effects of extraversion on reading comprehension performance, a correlational analysis was conducted on extraversion scores and times taken in each condition. Whilst there were moderate to strong 
correlations between the task completion times, this analysis revealed that extraversion did not significantly correlate with the times taken to complete the comprehension task in any of the conditions. All three correlations with Extraversion were not significant $(-.02<r<-.08)$

\section{Insert Table 2 here}

\section{Discussion}

We believe this is one of a very few studies to use a within-subject design and one to examine the effect of sirens on cognitive processing (Enser et al., 2017). In line with our predictions, the data indicated a significant effect of distraction that varied as a function of the type of background sound. As expected, participants were fastest in silence and slowest with the sound of sirens. These findings are in line with much of the previous literature (Banbury \& Berry, 1998; Dobbs, Furnham, \& McClelland, 2011; Furnham \& Strbac, 2002; Ransdell \& Gilroy, 2001); cognitive performance declines in the presence of distracting background sound. This is known to educationists and those who do very demanding cognitive work: namely that they function more effectively in as near silent condition as possible.

Distracting noise, such as that of sirens, is usually annoying because it is out of an individual's control and cannot be predicted (Sailer \& Hassenzahl, 2000). Sirens often consist of wails and oscillations, are designed to be distracting and attention grabbing, and are qualitatively different from other types of background noise and music. For example, Avila, Furnham, and McClelland (2011) found that music did not adversely affect performance on tests of numerical ability.

In this study, the presence of white noise was found to slow performance - but not to the extent observed for the sound of sirens. We argue that the key difference 
between the white noise and sirens is that sirens act as a signal to danger but white noise does not and this may be related to differences in brain activation. Surguladze et al. (2003) found a differential increase in activity in extrastriate areas and the amygdala in response to "high-intensity fearful expressions" (p. 1317). The authors suggested that the different patterns of response to different types of emotional expression "allows the preferential direction of visual attention to signals of imminent danger than to other, less-salient emotional stimuli" (p. 1317). It is conceivable that similar differences would be found for auditory attention to danger signals. Thus greater levels of attention would be directed to the sirens, than to non-threatening white noise resulting in a slowing of task performance. According to Graydon and Eysenck (1989), this would have resulted in a greater distraction effect due to the cognitive processing demands placed on the individual by the stimuli.

These findings were however inconsistent with previous literature (Campbell \& Hawley, 1982; Dobbs et al., 2011; Furnham \& Strbac, 2002), which provided supporting evidence for the Eysenckian hypothesis of cortical arousal. It was assumed that the sirens would act as a stimulating distractor and result in the introverts taking a greater amount of time to complete the reading comprehension task in the noise conditions compared to extroverts. However, this was not found to be the case. Interesting it may have had an effect on another classic personality variable, namely neuroticism. That is, trait neuroticism associated with anxiety, could be implicated in this situation, more than Extraversion, as the noise (particularly siren) distraction could have increased anxiety which may have impaired cognitive processing. There is a considerable literature in cognitive psychology which explains how neuroticism has a negative impact on memory processes (Robinson et al., 2013; Saylik et al., 2018) Equally, to measure the interaction between extraversion-introversion and stability- 
neuroticism may have shown that it is only particular types of extraverts (Choleric: Unstable/Neurotic Extraverst) that is negatively influenced by affective distraction.

There are a number of possible reasons why this study did not demonstrate a significant interaction between personality and background sound. Graydon and Eysenck (1989) claimed that one key factor is the task complexity. Both Dobbs et al. (2011) and Furnham and Strbac (2002) used more complex tasks than the reading comprehension task used in the present experiment. It is possible that the lack of complexity did not allow for the personality differences in cognitive performance to be revealed. However, Halin (2016) suggested that personality factors play a more important role when the task is less demanding.

Furthermore, there is also the issue of how extraversion is measured and whether the scale has more items concerning impulsivity than sociability. Had we used a longer and different measure of Extraversion it is possible we would have shown a stronger effect for personality.

Perhaps the most important finding in this paper is the "siren effect". Whilst research in this area have been concerned with various features of auditory distraction, there has been less interest in the affective strength of the distracting stimulus. Thus music-distraction studies have considered vocal vs orchestral, complexity, tempo, even musical key as well as loudness but very rarely the emotional or cognitive associations of the music. Ergonomists have concentrated mainly on the loudness (decibel level) of the distracting noise. This study has shown that sirens appear to be successful in what they are designed to do: namely alert people and to distract them from their current task whatever their personality profile.

People who live or work in large cities and offices are probably more used to sirens from police, fire and ambulance services and thus may be affected by them less 
which could be tested. Also, people recognise different sirens: internal fire alarms, car alert sirens and neighbour burglar alarms. These no doubt product different reactions from personal considerations of safety (in the case of internal fire alarm) to annoyance at an erratic and loud car alarm. This is an interesting area for possible further study for those interested both the safety and ergonomic issues.

Relevant to this study there is research into the potential detrimental impacts of cognitive performance from other auditory stimuli that, similar to sirens, are designed to alert and draw attention to serious problems These occur in a variety of safety critical settings such as nuclear power control rooms, air traffic control rooms, cockpits and operating theatres where there are background alarms that could be very distracting, particularly to those who are not the intended user of the alarm. The consequence of alarms are that they are heard by many people for whom they are not always intended and which can be very seriously affected by them, having a deleterious effect on their cognitive functioning.

Like all others, this study had limitations. It would be desirable to replicate it with a larger sample size, using a wider yariety of cognitive tasks, and exploring in more detail noise sensitivity and its relationship with personality type. It would be interesting to consider where people worked (i.e. the acoustic nature of their work environment) and the extent to which they may have acclimated to noisy distractors. Given that this study was conducted in and on people living in central London, which is a very noisy city, it seems the results of this study suggests this sort of habituation still does not prevent the effects of noise distraction on cognitive tasks. Equally as mentioned above it would have been desirable to measure other personality variables such as neuroticism as discussed above. 


\section{References}

Avila, C., Furnham, A., \& McClelland, A. (2011). The influence of distracting familiar vocal music on cognitive performance of introverts and extraverts. Psychology of Music, 40(1), 84-93. http://doi.org/10.1177/0305735611422672

Banbury, S., \& Berry, D. C. (1998). Disruption of office-related tasks by speech and office noise. British Journal of Psychology, 89(8), 499-517.

Belojevic, G., Jakovljevic, B., \& Slepcevic, V. (2003). Noise ând mental performance: Personality attributes and noise sensitivity. Noise and Health, 6, 77-89.

Campbell, J. B., \& Hawley, C. W. (1982). Study Habits and Eysenck's Theory of Extraversion-Introversion. Journal of Research in Personality, 146(16), 139146.

Cassidy, G., \& MacDonald, R. (2007). The effect of background music and background noise on the task performance of introverts and extraverts. Psychology of Music, 35(3), 517-537.

Charness, G., Gneezy, U., \& Kuhn, M. A. (2012). Experimental methods: Betweensubject and within-subject design. Journal of Economic Behavior \& Organization, 81, 1-8.

Dénes, J. \& Keedwell, A. D. (1974). Latin squares and their applications. New York-

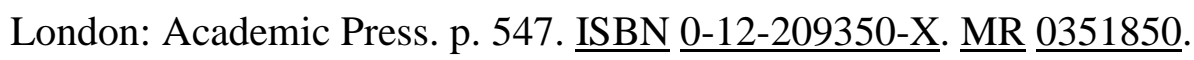

Dobbs, S., Furnham, A., \& McClelland, A. (2011). The Effect of Background Music and Noise on the Cognitive Test Performance of Introverts and Extraverts. 
Applied Cognitive Psychology, 25(2), 307-313. http://doi.org/10.1002/accp.1692

Enser, M., Moriceau, J., Abily, J., Damm, C, Occhiali, E., Besnier, E., et al. (2017). Background noise lowers the performance of anaesthesiology residents' clinical reasoning when measured by script concordance: A randomised crossover volunteer study. European Journal of Anaesthesiology, 34(7), 464-470.

Eysenck, B., Eysenck, H., \& Barrett, P. (1985). A Revised Version of the Psychoticism Scale. Personality and Individual Differences, 6(1), 21-29. http://doi.org/10.1016/0191-8869(85)90026-1

Eysenck, H. (1967). The Biological Basis of Personality. Springfield, IL.: Charles C. Thomas.

Eysenck, H. J. (1994). Personality: Biological foundations. In P. A. Vernon (Ed.), The neuropsychology of individual differences (pp. 151-207). Academic Press.

Faul, F., Erdfelder, E., Lang, A.-G., \& Buchner, A. (2007). G*Power 3: A flexible statistical power analysis program for the social, behavioral, and biomedical sciences. Behaviour Research Methods, 39(2), 175-191.

Furnham, A., \& Allass, K. (1999). The Influence of Musical Distraction of Varying Complexity on the Cognitive Performance of Extroverts and Introverts. European Journal of Personality, 13(1), 27-38.

Furnham, A., Gunter, B., \& Peterson, E. (1994). Television Distraction and the Performance of Introverts and Extroverts. Applied Cognitive Psychology, 8(6), 705-711. http://doi.org/10.1002/acp.2350080708

Furnham, A., \& Strbac, L. (2002). Music is as distracting as noise: the differential distraction of background music and noise on the cognitive test performance of 
introverts and extraverts. http://doi.org/10.1080/00140130210121932

Gonzalez, M. F., \& Aiello, J. R. (2019). More than meets the ear: Investigating how music affects cognitive task performance. Journal of Experimental Psychology: Applied, 25(3), 431-444. https://doi.org/10.1037/xap0000202

Graydon, J., \& Eysenck, M. W. (1989). Distraction and cognitive performance. European Journal of Cognitive Psychology, 1(2), 161-179. http://doi.org/10.1080/09541448908403078

Halin, N. (2016). Distracted while reading? Changing to a hard-to-read font shields against the effects of environmental noise and speech on text memory. Frontiers in Psychology, 7, Article 1196

Jafari, M., \& Kazempour, M. (2013). Review of low frequency noise effects on mental performance. Journal of Health, 3, 52-6

Landay, K., \& Harms, P. D. (2019). Whistle while you work? A review of the effects of music in the workplace. Human Resource Management Review, 29, 371-385. https://doi.org/10.1016/j.hrmr.2018.06.003

Lavie N. (2005). Distracted and confused?: Selective attention under load. Trends in Cognitive. Science. 975-82. 10.1016/j.tics.2004.12.004

Matthews, G., \& Amelang, M. (1993). Extraversion, Arousal Theory and Performance: A Study of Individual Differences in the EEG. Personality and Individual Differences, 14(2), 347-363.

Pearson Education, I. (2012). Pearson Longman. Retrieved November 19, 2016, from http://www.pearsonlongman.com/ae/marketing/sfesl/practicereading.html\#Using 
Qualtrics. (2005). Qualtrics. Prozo, Utah, USA. Retrieved from www.qualtrics.com

Ransdell, S. E., \& Gilroy, L. (2001). The effects of background music on word processed writing. Computers in Human Behaviour, 17(2), 141-148.

Robinson, O.J, Vytal, K., Cornwell, B.R., \& Grillon C. (2013) The impact of anxiety upon cognition: perspectives from human threat of shock studies. Frontiers in Human Neuroscience, 7:203. doi:10.3389/fnhum.2013.00203

Sailer, U., \& Hassenzahl, M. (2000). Assessing noise annoyance:an improvementoriented approach. Ergonomics, 43(11), 1920-1938. htt Avila, C., Furnham, A., \& McClelland, A. (2011). The influence of distracting familiar vocal music on cognitive performance of introverts and extraverts. Psychology of Music, 40(1), 84-93.

http://doi.org/10.1177/0305735611422672p://doi.org/10.1080/001401300501745 45

Saylik, R., Szameitat, A.J., \& Cheeta, S..(2018) Neuroticism related differences in working memory tasks. PLoS One, 13(12):e e0208248.

Shepherd, D., Heinonen-Guzejev, M., \& Heikkilä, K., (2015) Elucidating the relationship between noise sensitivity and personality. Noise and Health, 17, 166-171.

Smith, A. (1989). A review of the effects of noise on human performance. Scandivian Journal of Psychology, 30(3), 185-206.

Surguladze, S. A., Brammer, M. J., Young, A. W., Andrew, C., Travis, M. J., Williams, S. C. R., \& Phillips, M. L. (2003). A preferential increase in the extrastriate response to signals of danger. NeuroImage, 19(4), 1317-1328. http://doi.org/10.1016/S1053-8119(03)00085-5 
Ylias, G., \& Heaven, P. C. L. (2003). The influence of distraction on reading comprehension: a Big Five analysis. Personality and Individual Differences, 34(6),1069-1077.

http://doi.org/http://dx.doi.org.libproxy.ucl.ac.uk/10.1016/S0191-8869(02)00096-X

Table 1. The means (in seconds) and standard deviations of time taken to complete a variation of the reading comprehension task in each condition of silence, white noise, and sirens.

\begin{tabular}{lcc}
\hline Condition & $M$ & $S D$ \\
\hline Silence & 135.10 & 40.44 \\
White Noise & 155.16 & 38.50 \\
Sirens & 184.06 & 49.10 \\
\hline
\end{tabular}

Table 2. The bivariate correlations of time taken to complete a reading comprehension task in each condition and extraversion scores.

\begin{tabular}{llll}
\hline & Silence & White Noise & Sirens \\
\hline White Noise & $.763^{* *}$ & & \\
Sirens & $.468^{* *}$ & $.604 * *$ & \\
Extraversion & -.025 & -.078 & -.077 \\
& & \\
$* * \mathrm{p}<.01$
\end{tabular}

